\title{
Fecundity and larval development of Monochamus galloprovincialis (Coleoptera Cerambycidae) in experimental breeding
}

\author{
Fotini A. Koutroumpa, Bruno Vincent, Géraldine RouX-Morabito, Carine Martin, \\ François LIEUTIER*
}

Laboratoire de Biologie des Ligneux et des Grandes Cultures, UPRES-EA-1207, Université d'Orléans, BP6759, rue de Chartres, 45067 Orléans Cedex 2, France

(Received 31 January 2008; accepted 9 July 2008)

Keywords:

Monochamus galloprovincialis /

biology /

fecundity /

larval instars /

mortality /

experimental breeding

Mots-clés :

Monochamus galloprovincialis /

biologie /

fecundité /

stades larvaires /

mortalité /

élevage

\begin{abstract}
-The study aimed at clarifying basic life traits (fecundity, mortality and development) of Monochamus galloprovincialis, the vector of Bursaphelenchus xylophilus, the causative agent of the Pine Wilt Disease, in Portugal.

- Mating and oviposition experiments were conducted on P. sylvestris logs under laboratory conditions during two years. Larval development was followed outdoors.

- Fecundity was high, with 138.2 eggs per female.

- For the first time, the number of larval instars (4) in M. galloprovincialis was recognized and instars were described.

- Informations are provided on the shape and size of the larval galleries. Boring of galleries in sapwood and heartwood started at the third instar. All instars could overwinter but adults emerged simultaneously resulting in a univoltine life cycle for the majority of the individuals.

- An obligatory diapause in the forth instar was assumed. However, $8.1 \%$ of the insects had a two year development.

- Important differences in mortality were noted between the two experimental years, which could be explained by differences on the size of the breeding logs.

- There is a high biological proximity between M. galloprovincialis populations in France and those in Portugal and Northern Europe. However, a higher fecundity and longevity was observed in France, as well as a higher percentage of insects with a two year development, compared with portuguese populations.
\end{abstract}

Résumé - Fécondité et développement larvaire de Monochamus galloprovincialis (Coleoptera Cerambycidae) en élevage.

- L'objectif de l'étude était de clarifier certaines caractéristique de base -fécondité, mortalité, développement) de Monochamus galloprovincialis, le vecteur de Bursaphelenchus xylophilus, agent du dépérissement des pins au Portugal.

- Durant deux ans, des expériences d'accouplement et de ponte ont été conduites sur rondins de $P$. sylvestris au laboratoire. Le développement larvaire a été suivi en extérieur.

- La fécondité a été élevée, avec 138.2 œufs par femelle.

- Pour la première fois chez M. galloprovincialis, le nombre de stades larvaires (4) de M. galloprovincialis a été défini et ceux-ci ont été décrits.

- Des informations sont fournies sur la forme et la taille des galleries larvaires. Le forage des galeries dans l'aubier et le bois de cœur commence au troisième stade. Tous les stades peuvent hiverner mais les adultes émergent simultanément, ce qui conduit à un cycle annuel pour la plupart des individus.

- Une diapause obligatoire intervient au quatrième stade. Cependant, $8.1 \%$ des insectes ont un développement sur deux ans.

- Des différences importantes ont été notes entre les deux années d'étude. Elles pourraient s'expliquer par la taille différente des rondins d'élevage.

\footnotetext{
*Corresponding author: francois.lieutier@univ-orleans.fr
} 


\begin{abstract}
- Il existe une proximité biologique élevée entre les populations françaises de M. galloprovincialis et celles du Portugal et d'Europe de Nord. Cependant, une fécondité et une longévité plus élevées, ainsi qu'une proportion plus haute d'insectes ayant un développement sur deux ans, ont été observées en France par rapport aux populations portugaises.
\end{abstract}

\section{INTRODUCTION}

Longhorn beetles of the genus Monochamus (Coleoptera Cerambycidae) are generally recognized as non important secondary pests (Hellrigl, 1971). Nevertheless, because of their association with the Pine Wood Nematode (PWN) Bursaphelenchus xylophilus (Nickle, 1970; Steiner and Buhrer, 1934) (Nematoda: Aphelenchoididae), the causative agent of the Pine Wilt Disease (PWD) (Kiyohara and Tokushige, 1971), their role as forest pest has been largely reconsidered. A Pest Risk Analysis (PRA) on the European Union territories (as PRA area) recognized five endemic species of Monochamus (i.e. M. galloprovincialis (Olivier), M. sutor (Linnaeus), $M$. sartor (Fabricius), M. urussovi (Fischer) and M. saltuarius (Gebler)) as potential vectors of B. xylophilus in Europe, and many pine species with frequent occurrence in Europe as susceptible pine hosts (Evans et al., 1996). In 1993, the OEPP/EPPO (Directive 77/93, EEC) declared the PWN a quarantine organism in the European Union territories (Evans et al., 1996).

Seven Monochamus species have been reported so far to be the only worldwide vectors of the PWN capable to transmit it to pines: M. carolinensis (Olivier), M. mutator (LeConte), M. scutellatus (Say) and M. titillator (Fabricius) in North America, M. alternatus (Hope) and M. saltuarius (Gebler) in East Asia (Evans et al., 1996) and M. galloprovincialis (Olivier) in Portugal where the nematode was discovered in 1999 in Pinus pinaster, near the port of Setubal (Mota et al., 1999; Sousa et al., 2001). However, some other Cerambycidae and some Buprestidae and Curculionidae species have been found carrying this pest but no successful transmitting activity to pines has been proved (Linit, 1988; Sousa et al., 2001; 2002).

A correct evaluation of the risks of damage extension in regions where the nematode has not been introduced yet must consider the vector insect as an essential factor. However, until their association with the PWN was recognized, very little had been known on the biology and ecology of Monochamus species. Many studies exist on the Asian and the North American species (Akbulut et al., 2004; Anbutsu and Togashi, 2000; 2002; Togashi, 1995; 1997; Togashi et al., 1997). Some aspects of the biology of European species have been presented by Hellrigl (1971) Starzyk and Hilszczanski (1997), and Tomminen (1993) but their observations were made on Northern European populations. According to these authors, after emergence, the beetle's maturation feeding takes place on the twig bark of healthy pine trees. When matured, the females use their mandibles to excavate slits in the bark of recently killed or weakened pine tree and lay one or two eggs in each wound. There are two periods of PWN penetration on pines: during beetle maturation feeding (Hellrigl, 1971; Naves, 2007; Togashi et al., 2004) when both sexes transmit the nematodes to healthy host trees via the feeding wounds, and during oviposition when females transmit them to dying trees via the oviposition wounds (Edwards and Linit, 1992; Mamiya and Enda, 1972; Morimoto and Iwasaki, 1972; Wingfield and Blanchette, 1983). The nematodes enter the beetle's tracheal system via the spiracles during the pupal stage (Hellrigl, 1971; Naves, 2007).

Since M. galloprovincialis was proved to be the vector of the PWN in Portugal, several studies have been conducted on this species (Naves et al., 2005; 2006a; 2006b). Nevertheless this insect has not been, so far, the subject of an exhaustive survey in France and details of its biology are still unknown. Even though B. xylophilus has not yet been found in France (Vincent et al., 2008), the risks of its introduction in this country are very serious. France could easily play the role of a bridge to the propagation of the PWN from Portugal to the rest of Europe and, despite the efforts for surveillance, another accidental introduction from another continent cannot be excluded. Furthermore, bioclimatic parameters in France, such as temperatures, hosts and vectors, seem adequate for the nematode installation and propagation (Evans et al., 1996). Consequently, clarifying in depth all possible aspects of the life of its vector appears essential to evaluate the modalities of extension, the risks of damage, as well as to build survey and control programs in case the PWN would be introduced.

The aim of this paper is to report on a biological study of M. galloprovincialis, the most abundant French Monochamus species. Laboratory experiments on fecundity, development and mortality were conducted on Pinus sylvestris. Questions like larval instars' number, size and duration, as well as parameters influencing fecundity level and frequency, and mortality were investigated.

\section{MATERIALS AND METHODS}

\subsection{Insects and breeding logs}

All M. galloprovincialis adults as well as the oviposition material (P. sylvestris trees) were collected from Lorris forest, near Orléans (France).

Laboratory breeding experiments were conducted during two years (2004 and 2005). For 2004, 18 adults (9 males and 9 females) were captured in July. Beetles for the 2005 experiments were either adults that emerged during summer 2005 from the laboratory experiments of 2004 ( 11 males and 9 females), or adults that emerged from trap trees (5 males and 7 females). In that later case, $P$. sylvestris trees were cut down on July 2004 and left in the forest until end of spring 2005. On May 2005, branches of these trees, attacked by Monochamus, were cut into logs, brought to the laboratory, and stored in plastic containers (53 cm high, $47.5 \mathrm{~cm}$ diameter) covered with tulle, until Monochamus adults emerge in summer 2005.

Healthy $P$. sylvestris trees were cut down at the end of June, each year ( 2 trees in 2004 and 3 trees in 2005) to be used as oviposition 
substrates. Branches and about $50 \mathrm{~cm}$ of the upper part of the trunk were cut into logs and brought to the laboratory. The logs were carefully examined in order to exclude those already infested by Monochamus beetles and their ends were sealed with paraffin to slow down desiccation. Logs were kept at $4{ }^{\circ} \mathrm{C}$ until use.

\subsection{Adult maturation, mating and oviposition}

Maturation nutrition, mating and oviposition were studied at $23^{\circ} \mathrm{C}$ in the laboratory. During the maturation feeding period, adults were kept separately in plastic boxes $(26.5 \times 13.5 \times 7.5 \mathrm{~cm})$ containing moistened paper and pierced by a $5 \mathrm{~cm}$ diameter aeration hole covered with $1 \mathrm{~mm}$ mesh tulle. Newly emerged adults were introduced into the boxes and were supplied with fresh young twigs every two days for 6 to 38 days. Based on observations by Walsh and Linit (1985), Jikumaru et al. (1994), Togashi (1997), and Nakayama et al. (1998), they were allowed to mature in these boxes during 13 to 24 days before their use in the oviposition experiment.

For the oviposition experiment, mates were chosen within similar emergence dates and size ranges. Adult body length was measured from the pronotum to the end of elytra. The insects were photographed with a Canon PowerShot A80 digital camera through the ocular of a dissecting microscope, and their body length was measured on the pictures by using ImageJ $1.32 \mathrm{j}$. with the same method as for larvae. Couples were placed in plastic boxes, with fresh twigs for feeding and a $\log$ for oviposition. Descendants from the same parents were never matched together to prevent consanguinity and males that died during the first week after mating were replaced by new ones, with respect to the emergence date and body size of the female. In 2004, oviposition experiment started the 1st of July and ended in October with the death of females. In 2005, it started the 7 th of July and each female was allowed to oviposit for about one month. Then, the experiment had to be stopped because of technical restrictions. For the two years the beginning of the female oviposition depended on their emergence date and the oviposition date of each egg was defined by considering the 1 st July as day 0 . The logs were checked daily, under a binocular lens, and oviposition slits were recorded. When more than five slits with jelly emitted by the female during oviposition were observed, the log was replaced by a new one. The number of slits with and without jelly was recorded as well as the length, diameter and bark thickness of the logs.

Couples, with both male and female coming from the forest (captures or emergences from trap logs), were grouped for analyses as A4 couples (for 2004, 10 couples) or A5 (for 2005, 3 couples). Couples with both sexes coming from the 2004 breeding were grouped as B couples ( 8 couples). When males and females were a mix of adults that emerged from the breeding logs and the trap logs coming from the forest, they were grouped as $\mathrm{C}$ couples (4 couples).

Fecundity was estimated as the total number of eggs per female, based on the number of slits with jelly, following Anbutsu and Togashi (1997) who proposed, for M. alternatus, that jelly was a reliable prediction of egg deposition, and slits without jelly were inspected for the presence of eggs. In order to determine how the fecundity evolved during the oviposition period (between the first and the last egg laid by a female), three females with different total fecundity rates were chosen among the A4 group.

\subsection{Larval development}

The totality of the 273 logs with eggs from the oviposition experiment were placed in containers covered with tulle for aeration and protection and stored outdoor, but sheltered from rain to avoid extensive fungal development. In 2004, no attention was given to the direction of the logs in the containers, but in 2005, logs with eggs were placed vertically with respect to their natural position.

Every 15 days from July 15 to October, one to three larvae from each couple were extracted from the oviposition logs, in order to follow the larval development. Logs were examined by following the galleries from the oviposition slit under the bark, then in the phloem and eventually in the sapwood, until the larvae were found, thus giving their exact location in the log. When phloem galleries were empty, logs were sliced to look for larvae inside the sapwood and extract them. The extractions stopped in October and started again in February (with one month intervals) until June when adults begun to emerge. Depending on the total number of logs used by each couple to complete their oviposition, 12.5 to $45.5 \%$ of the logs were kept intact during the whole developmental period and used as control logs. The control logs were opened only at the end of the developmental period. This final extraction occurred end of February 2007. Dead and alive specimens were counted and measured. This period corresponded to the third year of development for the 2004 ovipositions and to the second for the 2005 .

Head capsule width and length, as well as body weight and length were measured with the same method as for adults' body size, to later characterize larval instars. Body color and presence of fecal materials in the intestine were noted. Larvae with milky white body color and with fecal materials in the intestine were considered to be in feeding activity, whereas those yellowish white to yellow with empty intestine were considered to be in diapause (Naves, 2007; Togashi, 1991a; 1991b). When all larvae had been extracted from a log, this log was sliced in order to determine the size and shape of the galleries.

To determine the size limits of each larval instar, we used both histograms built from head capsule widths measurements and histograms built with head capsule length measurements. They generally gave the same instar limits, with however always less overlapping between instar in the case of width measurements. For these reasons, we followed the indications of head capsule width when the two parameters did not indicate the same instar. The extreme values of instar were then used to define the instars of each larva and the results were subsequently used to determine the number of larvae in each instar. The minimum durations of larval instars were approached by plotting, for each stage separately, the age of each larva at extraction against the day of oviposition. In these conditions, for a given oviposition day, the lowest age value gives the closest approximation of the minimum development duration from oviposition day to the end of the previous stage.

Daily minimum and maximum temperatures during 2004-2005 for Orléans were obtained from Bricy meteorological station $(25 \mathrm{~km}$ NW from the experimental site).

\subsection{Mortality}

Mortality was studied only for the control logs, because those logs had not been disturbed by larval extractions during development. The total survival was obtained by dividing the number of adults by the number of eggs laid. In these calculations, the fourth instar larvae 


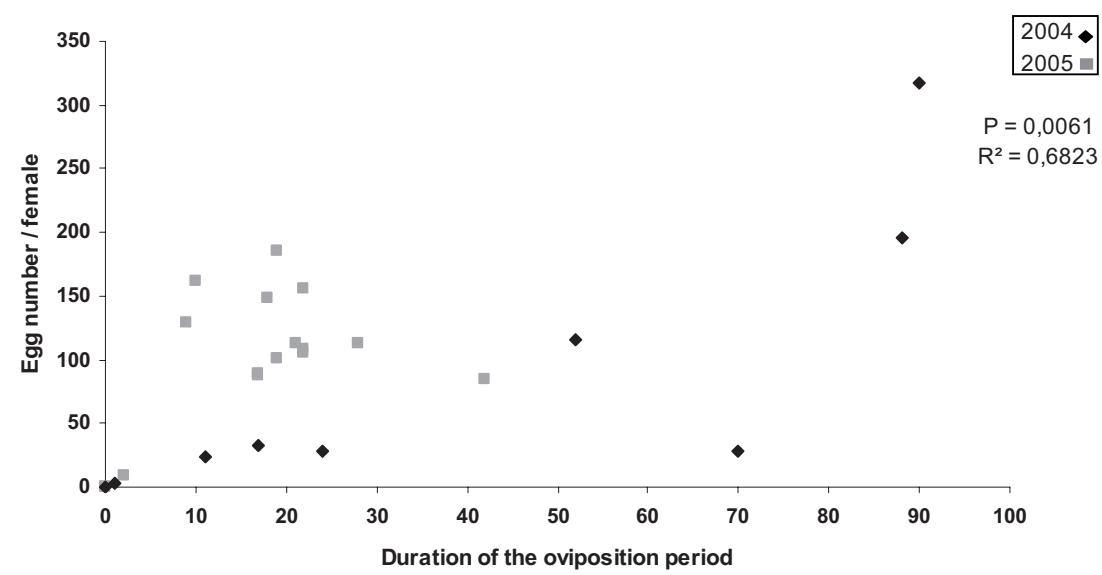

Figure 1. Total fecundity of females in relation to the duration of the oviposition period. Curve and equation are given for 2004.

that were found alive the second spring of their development were also taken into account (as adults) because they would probably have emerged as adults on the following summer.

\subsection{Statistical treatments}

Means were compared with the GLM procedure followed by a Sheffe's test. When the data distribution was not normal, the non parametric test of Wilcoxon was used. Linear regressions were calculated. Differences were considered significant for $P \leq 0.05$. Mean values are presented with their standard error. All statistical tests and calculations were performed with the SAS statistical program package (SAS Institute, 1987).

\section{RESULTS}

\subsection{Fecundity}

Eggs were always laid in the subcortical area. $71.55 \%$ of the slits excavated by the females were sealed with jelly and were considered to include at least one egg. Only $5.5 \%$ of the slits not plugged with jelly contained eggs. Two eggs were found in the same slit at only three occasions and, even though checking all slits was incompatible with the rest of the experiments, number of larvae found at the end corresponded to no more than one egg per slit. Fecundity did not differ significantly between the four groups (A4, A5, B and C) built according to their emergence conditions, considering that only A4 females were allowed to oviposit during their whole life (Tab. I). The 25 females used laid a total off 1700 eggs but nine of them died after mating or few days later (10 to 39 days in total) and laid between 0 and 32 eggs only. The remaining sixteen females lived at least 75 days and laid 85 to 196 eggs (mean $138.2 \pm 14.7$ ) most of them laying 100 to 115 eggs, at the exception of one female captured in the field (A4 group) that laid more than 300 eggs during its lifetime that lasted more than 113 days in the laboratory. Duration of the preoviposition period and female size were not correlated with fecundity. Mean body size of females was $17.1 \pm 0.6 \mathrm{~mm}$. Significant positive
Table I. Mean fecundity (SE) fecundity for each of the four groups of females and total. Groups made according to the emergence conditions of these females and their partners: forest (A4 for 2004 and A5 for 2005, laboratory breeding (B) or mix of the two (C).

\begin{tabular}{lc}
\hline Femalle group & Fecundity \\
\hline A4 & $74.30 \pm 33.45$ \\
A5 & $114.33 \pm 8.11$ \\
B & $110.75 \pm 17.44$ \\
C & $90.50 \pm 37.78$ \\
Total & $93.36 \pm 15.42$ \\
\hline
\end{tabular}

linear correlation was found between the fecundity and the duration of the oviposition period for 2004 experiment (Fig. 1). The correlation was not significant in 2005 although the same tendency existed.

The three A4 females used for the oviposition survey laid a total of 318, 196 and 115 eggs for the high, medium and low fecundity levels, and their total oviposition duration was 90 , 88 and 52 days, respectively (Fig. 2). Two oviposition phases could be distinguished for each female. In the first phase, corresponding respectively to 48,49 and $42 \%$ of the total oviposition duration, eggs were laid every day to every other day, and fecundity was 62,68 and $80 \%$ of the total fecundity. In the second phase (the remaining oviposition period), oviposition days were much less frequent. For each female, the number of eggs laid per oviposition day was very variable during the whole oviposition period. No significant relationship between oviposition day and the number of eggs laid per oviposition day was found.

\subsection{Development}

Eggs were $4.03 \pm 0.12 \mathrm{~mm}$ long and $1.22 \pm 0.04 \mathrm{~mm}$ wide $(n=12)$, and average length of pupae and adults were $19.97 \pm$ $0.93 \mathrm{~mm}(n=3)$ and $18.19 \pm 0.26 \mathrm{~mm}(n=121)$, respectively. 
Table II. Size characteristics of M. galloprovincialis larval stages.

\begin{tabular}{lcccr}
\hline \multicolumn{4}{c}{ Larvae } \\
\hline L1 & Body length $(\mathrm{mm})$ & Weight $(\mathrm{g})$ & Head capsule length (mm) & Head capsule width (mm) \\
L2 & 2.1 to $9.5-10.4$ & 0.001 to $0.014-0.018$ & 0.9 to $1.7-1.75$ & 0.5 to $0.89-1.03$ \\
L3 & $3.7-4.3$ to $19-21.4$ & 0.003 to 0.07 & $1.7-1.75$ to $2.76-2.87$ & $0.89-1.03$ to $1.55-1.62$ \\
L4 & 7.0 to $29.3-32.0$ & 0.005 to 0.21 & $2.76-2.87$ to $4.5-4.6$ & $1.55-1.62$ to $2.25-2.33$ \\
\hline
\end{tabular}
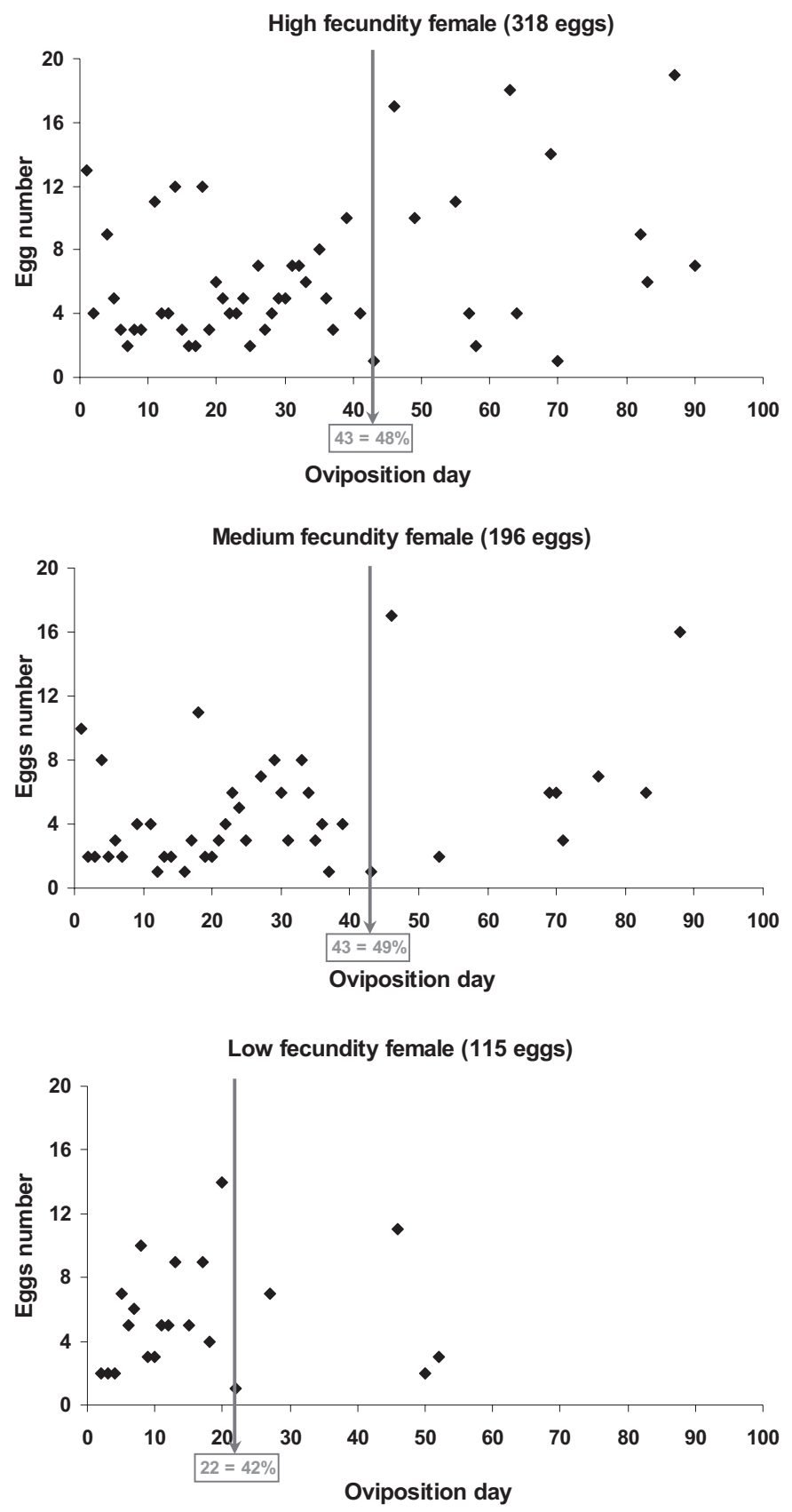

Figure 2. Egg distribution with time for three females of the A4 group.
Table III. M. galloprovincialis localization in the logs.

\begin{tabular}{lcccl}
\hline & Bark & Sapwood & Heartwood & $\begin{array}{l}\text { Pupal } \\
\text { chamber } \\
\text { (sapwood) }\end{array}$ \\
\hline Egg & $100 \%$ & & & \\
L1 & $100 \%$ & & & \\
L2 & $100 \%$ & & $16.4 \%$ & \\
L3 & $78.7 \%$ & $4.8 \%$ & $62.6 \%$ & $3.4 \%$ \\
L4 & $28.1 \%$ & $5.9 \%$ & & $100 \%$ \\
Pupae & & & & $100 \%$ \\
Adult & & & &
\end{tabular}

\subsubsection{Characterization of larval instars}

Head capsule width and length were measured for 797 larvae. Frequency of these measurements showed four separate maxima for both width and length, corresponding to four larval instars (L1, L2, L3 and L4) (see Fig. 3 for the width as an example). Size limits between instars were not very accurate, probably as a consequence of overlapping between the upper size limit of an instar and the lower size limit in the following one. Based on these observations, larval measurements and developmental stages characteristics are given in Table II.

Depending on their instar, larvae could be located in all parts of the log (Tab. III and Fig. 4). Sapwood and heartwood begun to be bored at the third larval instar. Gallery shape was noted for 87 galleries in both 2004 and 2005 and two shapes of galleries were observed (Fig. 4): $58.6 \%$ were U shaped, 36.8\% were $\mathrm{S}$ shaped, and $4.6 \%$, located near the ends of the log, had no special shape and were short. Gallery orientation was noted for 128 galleries in 2005: 79.7\% went up, following the natural direction of the log whereas $10.9 \%$ were oriented in the opposite direction; 9.4\% started with a down going direction (most of the times the beginning of these gallery was at the upper end of the $\log$ ) but then they turned so that they could finally have an up going direction. Galleries size is given in Table IV. Pupae were only found in pupal chamber in the sapwood from which adults emerged through a circular hole in the bark.

\subsubsection{Head capsule size in relation to larval age}

Head capsule width distribution according to the age of larvae at extraction was the same for the two years and did not 
Table IV. Galleries size for M. galloprovincialis. All measures are given in $\mathrm{cm}$.

\begin{tabular}{lllllll}
\hline Species & & $\begin{array}{l}\text { Sapwood } \\
\text { gallery (1) }\end{array}$ & $\begin{array}{l}\text { Heartwood } \\
\text { gallery (2) }\end{array}$ & $\begin{array}{l}\text { Total } \\
(1)+(2)\end{array}$ & $\begin{array}{l}\text { Pupal } \\
\text { chamber } \\
\text { length }\end{array}$ & $\begin{array}{l}\text { Pupal } \\
\text { chamber } \\
\text { width }\end{array}$ \\
\hline M. galloprovincialis & $\min$ & 1.00 & 1.00 & 3.00 & 1.50 & 0.50 \\
& $\max$ & 4.50 & 13.70 & 16.10 & 6.40 & 0.40 \\
diameter & 1.60 & 1.00 \\
\hline
\end{tabular}

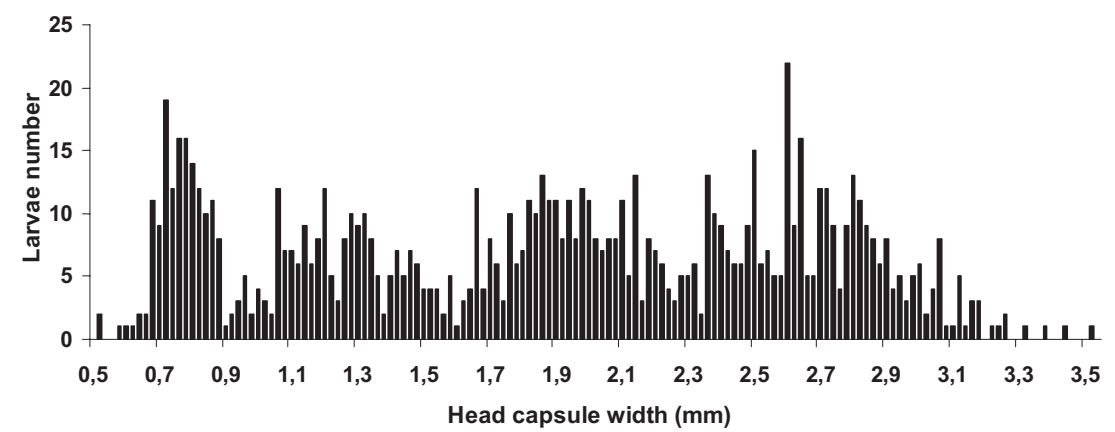

Figure 3. Frequency distribution of head capsule width for 797 larvae of M. galloprovincialis.

differ among parents' emergence origin (forest, trap logs and breeding logs) (data not shown). There were four groups of age corresponding to the periods of larval extraction (Fig. 5). Larvae that lived through a second and a third winter were mainly fourth instar larvae. They did not especially correspond to eggs laid at the end of the first summer (Fig. 6d) but developed in significantly bigger logs than larvae extracted after the first winter. Log mean surface was $539.8 \pm 56 \mathrm{~cm}^{2}$ for the larvae extracted after the first winter and $836.1 \pm 121.9 \mathrm{~cm}^{2}$ for the larvae extracted after the second winter $(P=0.0150)$ while log mean volume was respectively $969.1 \pm 175.1 \mathrm{~cm}^{3}$ and $2109.5 \pm 527.9 \mathrm{~cm}^{3}(P=0.0163)$.

\subsubsection{Development duration}

Figure 6 represents the relation between age at extraction (larvae) or at emergence (adults) and oviposition day, for each larval instar and for adults. Only the larvae of which the instar number was certain were taken into account. Minimum development duration from the oviposition day was 8 days for egg hatching in 2005 (9 in 2004) (Fig. 6a), 12 days for L1 termination in 2005 (19 in 2004) (Fig. 6b), 26 days for L2 termination in 2005 (33 in 2004) (Fig. 6c), and 46 days for L3 termination in 2005 (53 in 2004) (Fig. 6d), while L4 larvae changed into pupae during spring and to adults the following summer (Fig. 6e). For most stages, when oviposition day increased, the minimum development duration from eggs first slightly decreased and then increased. All L1 larvae reached the L2 instar before winter in 2005, but not in 2004 (Fig. 6a). All eggs laid during the first 30 days of the oviposition experiment reached at least the L3 instar before winter since no L1 or L2 from these eggs was found in spring (Figs. 6a and 6b). Similarly, all eggs laid during the first 10 days of the oviposition experiment reached the L4 instar before winter since no

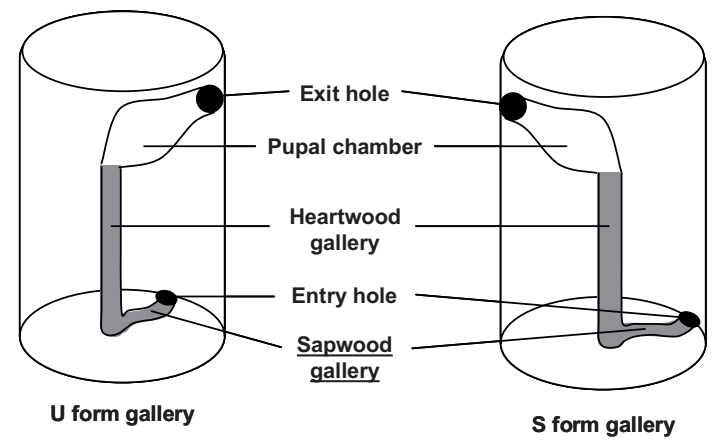

Figure 4. M. galloprovincialis gallery shapes.

L3 from these eggs was found in spring (Fig. 6c). Eggs laid after the 30th day could be at any stage during winter, and all larval instars were still present in spring. Among those eggs, overwintering larvae of any stage did not preferably originate from eggs laid at the end of the first summer. Similarly, L4 larvae coming from eggs laid during the whole oviposition period except the first 10 days were obtained at all three larval extraction periods (summer, first spring and second spring after oviposition). Those from eggs laid during the first 10 days were found at the first and second period only (Fig. 6d). 8.1\% of the L4 larvae were still alive in the heartwood at the last larval extraction period, after two breeding years (Fig. 6d).

Insect age at adult emergence (Fig. 6e) (indicating the total duration of development from oviposition to adult) varied very little compared to variations in age at any larval stage, whatever the date of oviposition. In addition, a significant negative regression indicated that total development from eggs to adults was shorter for the eggs laid in late summer than for those laid at the beginning of summer. One pre-emerging adult was found the second spring, indicating that its total larval 


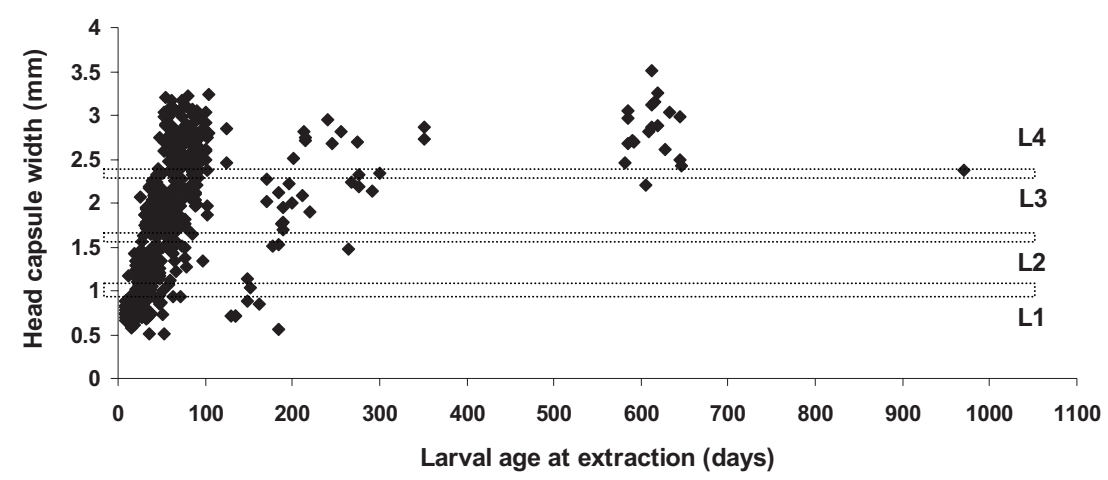

Figure 5. Head capsule width distribution in different larval extraction periods during $M$. galloprovincialis development. The first group of points corresponds to the summer extractions, and the second group to the spring extractions of the first year of larval development, with a gap due to the lack of extractions during winter. The two other groups of points correspond to larval extractions during spring of the second (2005 breeding only), and the third (2004 breeding only) years of larval development. Horizontal lines separate larval instars.

development took two years. At the emergence $42 \%$ of the adults were females and $58 \%$ males.

Temperatures were higher at the end of July and fell progressively during this period (Fig. 7).

\subsubsection{Mortality}

The mean total mortality rate differed between years $(83.5 \pm$ $4.0 \%$ in $2004 ; 55.2 \pm 5.0 \%$ in $2005 ; P<0.0001)$. Logs used for mortality estimations (control logs) differed significantly between years regarding their surface $(P<0.0001)$ and volume $(P<0.0001)$. Mean $\log$ surface was $306.5 \pm 17.8 \mathrm{~cm}^{2}$ in 2004 and $528.9 \pm 21.9 \mathrm{~cm}^{2}$ in 2005 . Mean $\log$ volume was $411 \pm 47.1 \mathrm{~cm}^{2}$ in 2004 and $791.5 \pm 67.6 \mathrm{~cm}^{2}$ in 2005. The smallest logs thus corresponded to the highest mortality rate. Total mortality was also significantly and negatively correlated with log surface and volume in $2004(r=-0.43$ in both cases, with $P=0.0034$ for surface and $P=0.0036$ for volume) but not in 2005. Mortality was not significantly correlated to egg density but was positively correlated to oviposition day during both years of experiment ( $r=0.42$ with $P=0.0027$ in 2004; $r=0.31$ with $P=0.0427$ in 2005). It was not possible to evaluate the mortality at larval instars because of the influence of frequent larvae extractions, but we never found dead pupae. $5.7 \%$ of the adults died while trying to bore their exit holes.

\section{DISCUSSION}

Some information was already given on M. galloprovincialis biology in previous studies, but in areas differing completely, in terms of climate, from that of the population we used. Our results thus allow previous information to be extended to or compared with central part of France. Furthermore, they bring completely new information on certain important aspects of M. galloprovincialis life cycle.

\subsection{Fecundity}

In our experiment, the fecundity of $M$. galloprovincialis females from the forest of Orléans (138.2 \pm 15.2 eggs per female) largely exceeds previous records in other European populations. Hellrigl (1971) gave a range of 45 to 87 eggs per female on $P$. sylvestris, Francardi and Pennacchio (1996) mentioned 37 eggs per female and Portuguese specimens laid in average 67 eggs in $P$. pinaster (Naves, 2007). Host trees may influence fecundity rates but Naves (2006a) did not found significant differences between fecundity in $P$. sylvestris and $P$. pinaster. Genetic differences between populations may also interfere. However, our results were obtained in laboratory, in better conditions than in nature where females have to search for adequate hosts and avoid predation, which could explain a higher fecundity. Our results with $M$. galloprovincialis also exceed the fecundity value given for its sister species $M$. sutor (Starzyk and Hilszanski, 1997). Nevertheless, they approach the values reported for Asian congeners (91.7 eggs for $M$. saltuarius and 124.1 for M. alternatus) (Jikumaru et al., 1994; Togashi, 1997) and for M. carolinensis (200 eggs) from North America (Akbulut and Linit, 1999; Walsh and Linit, 1985).

According to the three females used in our experiment, and as for the Portuguese M. galloprovincialis (Naves, 2007), the oviposition rhythm was higher during the first part of the oviposition period, but there was no relation between daily fecundity and oviposition day, as observed for M. saltuarius (Jikumaru et al., 1994) and M. alternatus (Togashi, 1997) in Japan. The relative duration of the intense oviposition period appeared not to depend on total fecundity of the female. However, total fecundity and total duration of oviposition may have been underestimated in our study since the females used came from field captures and might thus have already started ovipositing in the forest.

Females that lived longer laid more eggs, in agreement with the findings by Naves et al. (2006b) in Portugal for the same species, and Jikumaru et al. (1994) for M. saltuarius. The very weak fecundity of some females was therefore probably due to their early mortality. Female size and duration of the pre-oviposition period were not significantly correlated with 

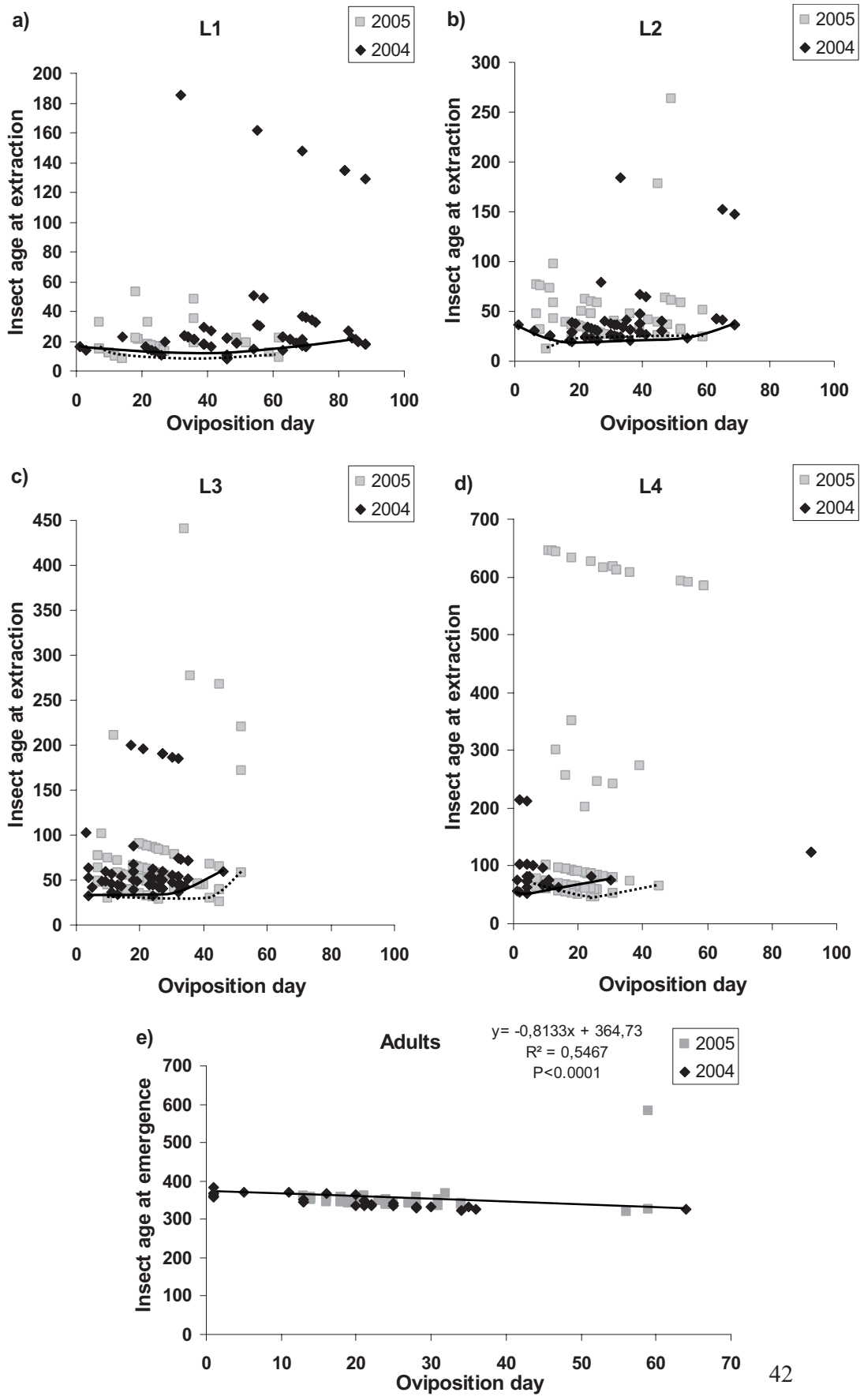

Figure 6. Insect age at extraction of the four M. galloprovincialis larval instars and at the emergence of the adult stage. For all the graphics values of 2004 are shown in black and those of 2005 in grey. Groups of points along the axis of insect age correspond to periods of extractions from logs. Curves with continue lines correspond to 2004 values and interrupted lines correspond to 2005 values. Curves in the first four graphics joint minimum values obtained for each larval instar and indicate minimum limits of the development of the previous instar. Curve in 6e corresponds to the regression line. 


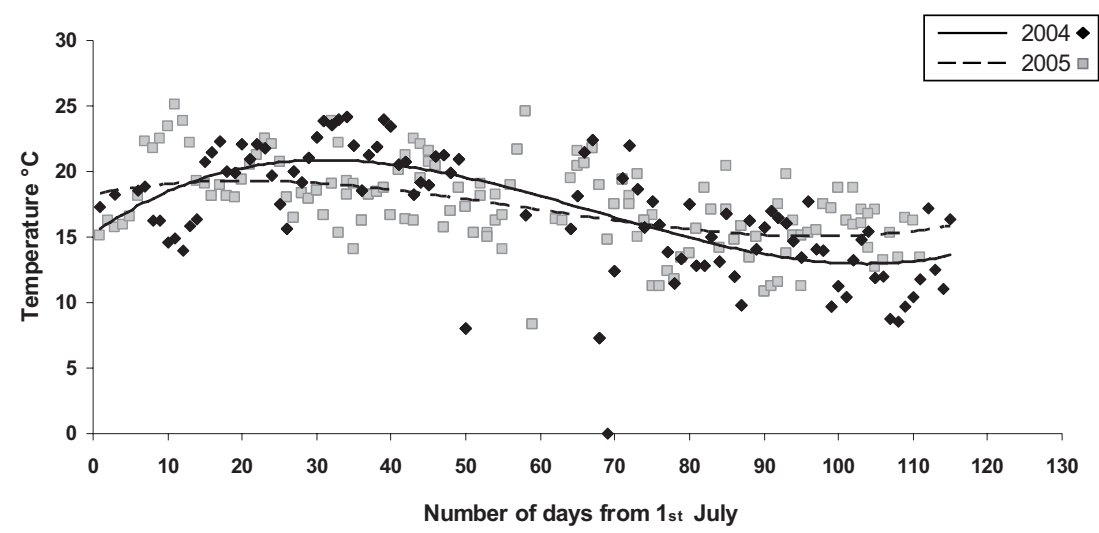

Figure 7. Mean daily temperature $\left({ }^{\circ} \mathrm{C}\right)$ variations between July and October in 2004 and 2005. Curves were adjusted to a third order polynom.

fecundity. This disagrees with Portuguese observations on $M$. galloprovincialis (Naves et al., 2006b), but observations on $M$. saltuarius and $M$. alternatus are consistent with our results (Jikumaru et al., 1994; Togashi and Magira, 1981).

\subsection{Longevity and mortality}

Excluding females with very weak longevity, M. galloprovincialis bred in our experimental conditions lived longer than what has been observed in previous experiments, probably because they were in laboratory conditions. Values of 75 to 113 days exceed the 65 to 80 days given by Hellrigl (1971) for this species, even though this author mentions the exceptional case of some specimens that lived 147 days. The minimum longevity found for females from the Orléans population was near the average value (78 days) found for this species in Portugal (Naves et al., 2006b) while M. alternatus specimens described by Togashi (1997) lived in average 82.8 days with a maximum of 145 days and $M$. saltuarius (Jikumaru et al., 1994) lived an average of 57.3 days (maximum 80 days).

Pupae zero mortality was evidently the lowest mortality observed among the different developmental stages. Even though it was close to the $0.8 \%$ found at this stage for the Portuguese populations (Naves, 2007). It seems however underestimated, especially when compared with the $6.2 \%$ found for $M$. alternatus (Togashi, 1990). On the other hand 5.7\% mortality of adults is only slightly higher than the $2 \%$ found for the Portuguese population, while $33.1 \%$ was reported for adult M. alternatus (Togashi, 1990). Discrepancies among studies could result from differences in experimental designs (laboratory conditions $M$. galloprovincialis versus natural conditions for $M$. alternatus).

The higher total mortality in the 2004 than in the 2005 experiment was certainly caused by too small a size of the breeding logs in 2004. This is confirmed by the fact that total mortality was significantly correlated with log size only in 2004, although among logs variations were comparable between years. Moreover, egg density in the logs was controlled and was not correlated to mortality. The $55.2 \%$ mortality found in 2005 is fully comparable to the $53 \%$ reported for the Portuguese populations of M. galloprovincialis (Naves, 2007). In
M. alternatus, Togashi (1990) indicates a total mortality ranging from $43 \%$ to $75 \%$ depending on the populations. Nevertheless, a high mortality $(88 \%)$ has been reported for $M$. carolinensis in North America (Akbulut et al., 2004).

\subsection{Larval development}

The number of larval instars had not been previously established in M. galloprovincialis. Our results clearly indicate that they are four, and we give their size characteristics. The number of larval instars may differ between field and laboratory conditions (Naves, personal communication). M. sutor, the sister species of $M$. galloprovincialis, has five larval instars (Starzyk and Hilszczanski, 1997), but M. alternatus is also known to have four larval instars (Togashi, 1990). All individuals of the two younger instars and most larvae of the third instar fed under the bark. Galleries in the sapwood and heartwood were initiated by the third larval instar, and most larvae of the fourth instar live in the heartwood, similarly to what has been found in M. sutor (Starzyk and Hilszczanski, 1997). The old larvae still need to feed under the bark when they retire in the pupal chamber (Hellrigl, 1971), probably explaining that up to $28 \%$ of the fourth instar larvae were under the bark.

In agreement with Hellrigl (1971), we found that M. galloprovincialis galleries can be $\mathrm{U}$ shaped or $\mathrm{S}$ shaped. By contrast, galleries of $M$. sutor are always U shaped (Starzyk and Hilszczanski, 1997). Those ones are also bigger since gallery size in the wood ranged from 8 to $28 \mathrm{~cm}$ for $M$. sutor, against 3 to $16.1 \mathrm{~cm}$ for M. galloprovincialis (our results). Similarly, pupal chamber of $M$. galloprovincialis was 1.5 to $6.40 \mathrm{~cm}$ long (our study) compared to 3.2 to $6.5 \mathrm{~cm}$ for M. sutor (Starzyk and Hilszczanski, 1997). Using breeding $\operatorname{logs}$ for the former may have however influenced gallery length.

The duration of larval development varied greatly between larvae, even in a same stage. Temperature certainly played a role. Indeed, the decrease followed by an increase of the minimum development duration from eggs to the beginning of most larval stages, when day of oviposition increase, might be explained, at least in 2004 , by the increase followed by the decrease of the daily mean temperature between July and 
October. Log quality may also interfere. Since they had been stored a longer time, logs used at the end of summer might have been of lesser quality than those used at the beginning. However, temperature and $\log$ quality, combined with day of oviposition, cannot explain the huge variations in insect age observed among each larval stage. All larval instars were found both before and after winter, indicating that larval development was interrupted by winter. However, although eggs laid before day 30 of oviposition all reached the third larval instar before winter, overwintering larvae did not especially originate from eggs laid at the end of summer, contrary to what could have been expected from previous observations (Hellrigl, 1971). Moreover, the duration of the total development was shorter for eggs laid in late summer than for those laid in the beginning of summer. Much less age variations were also observed among insects at emergence than at any larval stage, even when considering the first year of development only. All these results indicate that in terms of development larvae issue from late eggs can catch up with those issue from early eggs. This is in agreement with the suggestion by Naves (2007) of a genetically-induced and obligatory period of dormancy/diapause during winter. Naves (2007) proved that this dormancy/diapause was associated with the last larval instar. Our findings agree and indicate that it occurs at the fourth one.

We observed that quite a high proportion $(8.1 \%)$ of fourth instar larvae were still observed at this stage after a second winter. They would probably have emerged as adults the following summer, which is corroborated by the finding of a preemerging adult at the same period. That these larvae were found in bigger logs than those extracted after the first winter suggests that food abundance and therefore food quality would slow down larval development, while low food quantity and quality would incite larvae to accelerate their development so that they are able to become adult before food deficiency. Such a possibility has already been proposed for M. alternatus (Togashi, 1991a; 1995). Experimental conditions have thus certainly interfered, but our observations suggest that, at least in certain conditions, larval diapause could be prolonged for at least one year. A two year development for some specimens of M. galloprovincialis has already been reported (Hellrigl, 1971; Naves, 2007; Tomminen, 1993). The percentage of such individuals is 5\% in Portugal (Naves, 2007) and 90\% in Southern Finland (Tomminen, 1993). Our findings of $8.1 \%$ for the Orléans specimens suggest a latitudinal influence on the frequency of individuals with a two year development.

The sex ratio at emergence (0.42) was in advantage of males, and slightly lower than in Portugal (0.48) for the same species (Naves, 2007) and than in Japan (0.49) for M. alternatus (Togashi and Magira, 1981).

Acknowledgements: The study was part of a research program granted by the Ministère de l'Agriculture, de l'Alimentation, de la Pêche et de la Ruralité (MAAPR). The Foundation Korialenio (Greece) contributed to the stay of F. Koutroumpa in France. The authors also thank INRA Orléans for providing space for outdoor breeding experiments and J. Garcia (INRA) for its technical assistance in the field.

\section{REFERENCES}

Akbulut S. and Linit M.J., 1999. Seasonal effect on reproductive peformance of Monochamus carolinensis (Coleoptera: Cerambycidae) reared in pine logs. Forest Entomol. 92: 631-637.

Akbulut S., Stamps W.T., and Linit M.J., 2004. Population dynamics of Monochamus carolinensis (Col., Cerambycidae) under laboratory conditions. J. Appl. Entomol. 128: 17-21.

Anbutsu H. and Togashi K., 1997. Oviposition behaviour and response on the oviposition scars occupied by eggs in Monochamus saltuarius (Coleoptera: Cerambycidae). Appl. Entomol. Zool. 32: 541-549.

Anbutsu H. and Togashi K., 2000. Deterred oviposition response of Monochamus alternatus (Coleoptera: Cerambycidae) to oviposition scars occupied by eggs. Agric. For. Entomol. 2: 217-223.

Anbutsu H. and Togashi K., 2002. Oviposition deterrence associated with larval frass of the Japanese pine sawyer, Monochamus alternatus (Coleoptera: Cerambycidae). J. Insect Physiol. 48: 459-465.

Edwards O. and Linit M., 1992. Transmission of Bursaphelenchus xylophilus through oviposition wounds of Monochamus carolinensis (Coleoptera: Cerambycidae). J. Nematol. 24: 133-139.

Evans H.F., McNamara D.G., Braasch H., Chadoeuf J., and Magnusson C., 1996. Pest risk analysis (PRA) for the territories of the European Union (as PRA area) on Bursaphelenchus xylophilus and its vectors in the genus Monochamus. Bull. OEPP 26: 199-249.

Francardi V. and Pennacchio F., 1996. Note sulla bioecologia di Monochamus galloprovincialis galloprovincialis (Olivier) in Toscana e in Liguria (Coleoptera: Cerambycidae). Redia 79: 153159.

Hellrigl K.G., 1971. La bionomie des espèces de Monochamus (Coleoptera, Cerambycidae) et leur importance pour la sylviculture et l'économie du bois. Redia 52: 367-511.

Jikumaru S. and Togashi K., 1996. Effect of temperature on the post-diapause development of Monochamus saltuarius (Gebler) (Coleoptera: Cerambycidae). Appl. Entomol. Zool. 31: 145-148.

Jikumaru S., Togashi K., Taketsune A., and Takahashi F., 1994. Oviposition biology of Monochamus saltuarius (Coleoptera: Cerambycidae) at constant temperature. Appl. Entomol. Zool. 29: $555-561$.

Kiyohara T. and Tokushige Y., 1971. Inoculation experiments on a nematode, Bursaphelenhus sp., on pine trees. J. Jpn. For. Soc. 53: 210218.

Linit M.J., 1988. Nematode-Vector relationships in the pine wilt desease system. J. Nematol. 20: 227-235.

Mamiya Y. and Enda N., 1972. Transmission of Bursaphelenchus lignicolus (Nematoda: Aphelenchoididae) by Monochamus alternatus (Coleoptera: Cerambycidae). Nematologica 18: 159-162.

Morimoto K. and Iwasaki A., 1972. Role of Monochamus alternatus (Coleoptera: Aphelenchoididae) as vector of Bursaphelenchus lignicolus (Nematoda: Aphelenchoididae). J. Jpn. For. Soc. 54: 177-183.

Mota M.M., Braasch H., Bravo M.A., Penas A.C., Burgermeister W., Metge K., and Sousa E., 1999. First report of Bursaphelenchus xylophilus in Portugal and in Europe. Nematology 1: 727-734.

Nakayama Y., Jikumaru S., and Togashi K., 1998. Reproductive traits and diel activity of adult Monochamus saltuarius (Coleoptera: Cerambycidae) at two different temperatures. J. For. Res. 3: 61-65.

Naves P., 2007. Biology of Monochamus galloprovincialis (Coleoptera, Cerambycidae) and its role as vector of the pine wood nematode Bursaphelenchus xylophilus (Nematoda, Parasitaphelenchidae) in Portugal. Doutoramento em Biologia (Biologia Populacional). Faculdade de Ciências. 
Naves P.M., Kenis M., and Sousa E.M., 2005. Parasitoids associated with Monochamus galloprovincialis (Oliv.) (Coleoptera: Cerambycidae) within the pine wilt nematode-affected zone in Portugal. J. Pest Sci. 78: $57-62$.

Naves P.M., Sousa E.M., and Quartau J.A., 2006a. Feeding and oviposition preferences of Monochamus galloprovincialis for certain conifers under laboratory conditions. Entomol. Exp. Appl. . 120: 99104.

Naves P.M., Sousa E.M., and Quartau J.A., 2006b. Reproductive traits of Monochamus galloprovincialis (Coleoptera: Cerambycidae) under laboratory conditions. Bull. Entomol. Res. 96: 289-294.

Nickle W.R., 1970. A taxonomic review of the genera of the Aphelenchoidea (Fuchs, 1937) Thorne, 1949 (Nematoda: Tylenchida). J. Nematol. 2: 375-392.

Pershing J.C. and Linit M.J., 1986. Development and seasonal occurence of Monochamus carolinensis (Coleoptera: Cerambycidae) in Missouri. Environ. Entomol. 15: 251-253.

Sousa E., Bravo M.A., Pires J., Naves P., Penas A.C., Bonifacio L., and Mota M.M., 2001. Bursaphelenchus xylophilus (Nematoda; Aphelenchoididae) associated with Monochamus galloprovincialis (Coleoptera; Cerambycidae) in Portugal. Nematology 3: 89-91.

Sousa E., Naves P., Bonifacio L., Bravo M.A., Penas A.C., Pires J., and Serrao M., 2002. Preliminary survey for insects associated with Bursaphelenchus xylophilus in Portugal. Bull. OEPP. 32: 499-502.

Starzyk J.R. and Hilszczanski J., 1997. Bionomics, ecology, and economic importance of Monochamus sutor (L.) (Coleoptera, Cerambycidae) in mountain stands of Picea abies (L.) Karst. Zesz. Nauk. AR w Krakowie. 326: 121-145.

Steiner G. and Buhrer E.M., 1934. Aphelenhoides xylophilus, n. sp. a nematode associated with blue-stain and other fungi in timber. J. Agric. Res. 48: 949-951.

Togashi K., 1990. Life table for Monochamus alternatus (Coleoptera, Cerambycidae) within dead trees of Pinus thunbergii. Jpn. J. Ent. 58: $217-230$.

Togashi K., 1991a. Different developments of overwintered larvae of Monochamus alternatus (Coleoptera, Cerambycidae) under a constant temperature. Jpn. J. Entomol. 59: 149-154.
Togashi K., 1991b. Larval diapause termination of Monochamus alternatus (Coleoptera: Cerambycidae) under natural conditions. Appl. Entomol. Zool. 26: 381-386.

Togashi K., 1995. Interacting effects of temperature and photoperiod on diapause in larvae of Monochamus alternatus (Coleoptera: Cerambycidae). Jpn. J. Ent. 63: 243-252.

Togashi K., 1997. Lifetime fecundity and body size of Monochamus alternatus (Coleoptera: Cerambycidae) at a constant temperature. Jpn. J. Ent. 65: 458-470.

Togashi K., Akita Y., Nakane I., Shibata Y., and Nakai I., 1997. Relatively larger eggs produced by smaller females of Monochamus alternatus (Coleoptera: Cerambycidae). Appl. Entomol. Zool. 32: 264-266.

Togashi K., Chung Y.J., and Shibata E. (2004) Spread of an introduced tree pest organism - the pinewood nematode. In: Hong S.K., Lee J.A., Ihm B.S., Farina A., Son Y., Kim E.S., and Choe J.C. (Eds.), Ecological issues in a changing world. Status, response and strategy, Kluwer Academic Publishers, pp. 173-188.

Togashi K., Jikumaru S., Taketsune A., and Takahashi F., 1994. Termination of larval diapause in Monochamus saltuarius (Coleoptera: Cerambycidae) under natural conditions. J. Jpn. For. Soc. 76: 30-34.

Togashi K. and Magira H., 1981. Age-specific survival rate and fecundity of the adult Japanese pine sawyer, Monochamus alternatus Hope (Coleoptera: Cerambycidae), at different emergences times. Appl. Entomol. Zool. 16: 351-361.

Tomminen J., 1993. Development of Monochamus galloprovincialis (Olivier) (Coleoptera, Cerambycidae) in cut trees of young pines (Pinus sylvestris L.) and log bolts in southern Finland. Entomol. Fenn. 4: 137-142.

Vincent B., Koutroumpa F., Altemayer V., Roux-Morabito G., Gévar J. Martin C., and Lieutier F., 2008. Occurrence of Bursaphelenchus mucronatus (Nematoda, Aphelenchoïdidae) in France and association with Monochamus galloprovincialis (Coleoptera: Cerambycidae). Ann. For. Sci. 65: 111.

Walsh K. and Linit M., 1985. Oviposition biology of the pine sawyer, Monochamus carolinensis (Coleoptera: Cerambycidae). Ann. Entomol. Soc. Am. 78: 81-85.

Wingfield M. and Blanchette R., 1983. The pine-wood nematode, Bursaphelenchus xylophilus, in Minnesota and Wisconsin: insect associates and transmission studies. Can. J. For. Res. 13: 1068-1076. 